\title{
Identifying sectoral management cultures through recruitment advertising
}

\author{
John Cullen \\ Centre for Management Research, Irish Management Institute, \\ Dublin, Ireland
}

Keywords Management culture, Management development, Private sector organizations, Public sector organizations, Non-governmental organizations, Ireland

Abstract Adapting the research methodology and framework utilised by Communal and Senior, this paper analyses messages conveyed by advertisements for senior management positions in the Irish national press with a view to discerning if there are sectoral differences in management cultures in Ireland. Following the literature review and presentation of the research methodology, a report on the overall findings of the data collected is presented. A qualitative comparison of messages about management cultures in the private, public and non-government organisation sector is presented. In some cases, quantitative data are employed to enhance the findings. Distinct messages about differing management cultures on a sectoral basis are uncovered throughout the research.

\section{Introduction}

There is an extensive body of literature that examines the effect of national culture on organisational and management culture. Communal and Senior's (1999) article in the Leadership \& Organization Development Journal provided an examination of the messages conveyed about British, French and German management and national cultures by analysing advertisements for managerial appointments. This paper seeks to adapt their methodology with a view to ascertaining the following:

(1) Are messages about differences in sectoral management cultures evident in recruitment advertising?

(2) If so, what sectoral differences pertaining to senior management positions are communicated?

This paper presents research findings in four sections. First, a review of literature, pertinent to national and organisational cultural analysis, Irish culture and management cultures in Ireland, is presented. The research methodology employed is then outlined. Overall findings arising from data collected over the three-month data-collection timespan is reported. Finally, a qualitative comparison of messages relating to each sectoral management culture is presented under five category headings. These findings are then discussed in terms of their relevance to management and organisation development. It is hoped that the findings will be of use to human resources managers, management development organisations, executive recruitment agencies, managers interested in determining the "fit" of their skills, experiences and personal traits in the organisational culture of a potential employer, and organisational cultural theorists. 
LODJ

25,3

280
Sector is a key issue to consider when evaluating management culture. Private sector organisations are primarily businesses which focus on generating profit; public sector organisations implement government policy and deliver statutory services and non-government organisations (or not-for-profit bodies, voluntary, community or "third sector" organisations, hereafter NGOs) are "any private organization that provides services of benefit to society without financial incentive" (Pappas, 1996). These sectoral definitions are difficult in themselves. O'Sullivan (1999) points out that the boundaries between the non-governmental and public sectors have become highly problematic. Public bodies and NGOs face the same difficulties that private organisations encounter (Bryson, 1995) and it would be wrong to assume that greater levels of managerial talent are expected in a particular sector. Parry and Proctor-Thomson (2003) write:

Unlike the private sector, however, the public sector is fraught with the paradox of requiring flexibility and innovation in order to cope with the changing demands of the environment, while at the same time maintaining a not-for-profit service and accountability to a diverse range of stakeholders, a focus which requires stability and the restraint of innovative propensities. Given these unique characteristics, the relationships between leadership, culture type, organisational climate and effectiveness within the public sector may not necessarily mirror those in private sector organisations.

There is strong evidence that different competencies and skills required for success differ by sector. It might be expected then, that different types of managerial skill are expected in different sectors, and this in turn has a profound impact on the type of management culture that emerges. For example, Kingston (2001) commenting on the civil service, wrote:

When the only serious reward lies in promotion to a higher level within the hierarchy, opportunities for this become all-important, but since promotions are decided primarily by absence of failure, it is those who are best at arranging for their "cover" who move up through the hierarchy at the expense of those who take the actual task of the Department more seriously.

Much of the literature pertaining to cultural analysis in the field of management research validates the importance of analysing national cultures in view of the growth of internationalisation:

As markets globalise, the need for standardisation in organisational design, systems and procedures increases. Yet managers are also under pressure to adapt their organisation to the local characteristics of the market, the legislation, the fiscal regime, the socio-political system and the cultural system. This balance between consistency and adaptation is essential for corporate success (Trompenaars and Hampden-Turner, 1997).

Comparative analyses of international and local practices have authenticated these concerns with regard to various management practices (Black, 1999: Lindholm, 2000; Robert et al., 2000). Definitions of culture have long problematised the social sciences, but Hofstede's (1980) identification of the specific elements of which national culture is composed did much to progress research in the field. Studies of organisational cultures are different to anthropological analyses of national culture (Wilkins and Ouchi, 1983). Hofstede (1991) has stated: 
Using the word "culture" for both nations and organisations suggests that the two kinds of culture are identical phenomena. This is incorrect: a nation is not an organization, and the two types of "culture" are of a different nature. The differences between national and organizational cultures is due to the different roles played in each by the manifestations of culture...

These manifestations are described as practices that include symbols, heroes and rituals, and values. Using a comparative sectoral lens generates an enhanced perspective of the internal differences in a national management culture. Dargie (2000) found that "Several studies, although fewer than might be assumed, have tried to directly compare public and private management". Dargie's (2000) research findings demonstrated "how different configurations of power and influence affect the roles and activities of the chief executives in different [public and private sector] organisations."

\section{Irish culture}

The influence of national culture on Irish management culture(s) is not the area under investigation in this paper. However, the question of national culture cannot be ignored in terms of the overall context of the research, especially as the question of culture in Ireland is one that is particularly problematic. Ireland has undergone massive political and social change over the last 50 years:

In the contemporary world, it would be difficult to find an example of such deep, intense and rapid transformation as has occurred in Ireland. In less than a half-century, Ireland experienced a metamorphosis which propelled it out of the pre-industrial condition. While failing to generate an industrial order, it has, as a kind of unintended consequence, managed to establish itself as a post-industrial enclave within global capitalism (Peillon, 2002).

Factors influencing these changes include:

- the strong economic recovery experienced in Ireland "from the prolonged slump of the 1980s to the boom of the 1990s" (Nolan et al., 2001);

- return emigration;

- growth of multiculturalism; and

- lessening influence of Catholic church.

In recent years many of the hegemonic forces which had previously exerted a strong influence on Irish society have been called into question as a result of revelations of abuses of power and corruption. Being "Irish" has changed and this rate of change accelerated over the last decade.

\section{Irish management culture(s)}

Schein (1996) identified three organisational subcultures: the operator culture ("an internal culture based on its operational success"); the engineering culture ("the designers and technocrats who drive the core technologies"); and the executive culture ("the CEO and his or her immediate subordinates ... CEOs, because of the nature of their jobs and the structure of the capital markets, also constitute a worldwide occupational community in the sense that they have common problems that are unique to their roles"). Schein posited that lack of cultural alignment between these organisational cultures was a key cause of failures in organisational learning. 
LODJ

25,3

\section{2}

Some lessons learned from existing research that are important to the study of executive/management culture(s) in Ireland are outlined below:

- Power-distance (usually influenced by aspects of religious life) is influenced by the limits of the Roman Empire as Ireland (Catholic but not Latin) has a similar power distance index score as Britain (mainly Protestant but not Latin). The Irish used Catholicism as a source of identity to protect themselves against non-Catholic enemies.

- Ireland demonstrates a low UAI (a greater willingness to take risks) and high MAS (assertiveness or ambitiousness) (Hofstede, 1980).

- "In the United States, as well as in other masculine cultures, such as Britain and Ireland, there is a feeling that conflicts should be resolved by a good fight: 'Let the best man win'. The industrial relations scene in these countries is marked by such fights. If possible, management tries to avoid having to deal with labor unions at all, and labor unions' behaviour justifies their aversion" (Hofstede, 2001).

- Ireland belongs to the political/cluster of "individualistic nations" among fast growing nations (Read, 1993).

- Irish corporate culture is strongly "task" rather than "person" oriented.

- Irish corporate culture is slightly more "egalitarian" than "hierarchical" (Trompenaars and Hampden-Turner, 1997).

- "Relatively weak uncertainty avoidance societies, such as the UK and the Republic of Ireland. . . will tend to be more relaxed about life and less risk-averse. People in these societies fell relatively secure."

- Ireland is among the societies whose employees say they have a low involvement in planning their daily work.

- Ireland is among the societies with a relatively high percentage of employees who agree that workplace relations between management and employees are either "very good" or "quite good."

- High commitment management practices are positively associated with individual performance in Ireland (Black, 1999).

- Along with other countries in the "Anglo Cluster":

- Ireland is characterised by an individualistic performance orientation;

- values gender equality but is male-dominated in practice;

- Irish people see effective leadership as affected by a combination of charismatic inspiration and a participative style (Ashkanasy et al., 2002).

\section{Methodology}

Job advertisements are principally conceived to recruit the best staff, but they also serve to lay certain sectors and professions open to scrutiny (Cullen, 2000).

Communal and Senior (1999) report that researchers have argued "that advertisements for managers can be assumed to reflect the spontaneous expectations and demands made upon managers in a particular culture." Employment advertisements describe 
the position available and list the necessary skills and competencies needed to fulfil the role. As such, they are public documents that provide raw material for cultural and occupational analyses.

Communal and Senior (1999) selected a major British, French and German newspaper over the course of one week. The first 100 advertisements for management positions were numbered. Their research proposition was that ten advertisements from each country were randomly selected for analysis. Following their literature review, Communal and Senior developed the following categories for comparison:

- role and personal attributes;

- educational requirements;

- experience required;

- package;

- method of responding to an advertisement; and

- language skills.

This methodology was adopted for this research with the following exceptions:

(1) Only advertisements for senior management positions were selected. Specifically these are management positions that are at the chief executive officer (CEO) level, or reporting directly the CEO or board of directors of the organisation.

(2) The timespan of the data collection was expanded from one week to three months (June, July and August 2002).

(3) The number of newspapers scanned for advertisements was increased to the appointments sections of seven Irish national newspapers, being:

- The Irish Examiner;

- The Irish Independent;

- The Irish Times;

- The Sunday Business Post;

- The Sunday Independent;

- The Sunday Times (Irish edition); and

- The Sunday Tribune.

(4) Quantitative data will be presented alongside the qualitative analysis where applicable. A quantitative analysis of the results from data collected is presented below.

(5) Communal and Senior assert that their language category of findings "although interesting to look at, is not directly relevant to management philosophy and practice and it is therefore difficult to comment on". For this reason it has not been included in the comparative sectoral analysis below. It is interesting that despite the insistence on strong communications skills in each sector that only one advertisement (in the private sector) sought knowledge of a European language other than English. Two of the public sector advertisements required some level of fluency in the Irish language.
Sectoral management cultures

283 


\section{LODJ}

25,3

284

Table I.

Number of senior management positions advertised by month

\section{Overall findings}

A total of 220 advertisements for the senior management positions were collected over the three months. A month-by-month breakdown is contained in Table I, and a broad sectoral analysis in Table II.

Two positions were advertised in semi-state bodies, and in a single case the sector was not stated.

The main types of positions available are reported in Table III.

Remuneration data were reported in 68 ( 31 per cent) of the advertisements. Of these, 43 stated salary ranges and 25 reported single point salaries. Treating the lower and single cases together, the results are reported in Table IV.

Treating the top salary point of the advertisements which stated salary ranges, the results are reported in Table $\mathrm{V}$.

\begin{tabular}{lcc}
\hline Month & Number & Per cent \\
\hline June & 64 & 29 \\
July & 85 & 39 \\
August & 71 & 32 \\
\hline
\end{tabular}

Table II.

Number of senior management positions advertised by sector

\begin{tabular}{lcc}
\hline Month & Number & Per cent \\
\hline Public & 88 & 40 \\
Private & 96 & 44 \\
NGO & 33 & 16 \\
\hline
\end{tabular}

\section{Table III.}

Types of senior management positions advertised

\begin{tabular}{lcc}
\hline Title & Frequency & Per cent \\
\hline Chief executive/CEO/MD & 18 & 8 \\
Director & 14 & 6 \\
Head of function/area & 81 & 37 \\
General manager & 55 & 25 \\
HR manager & 13 & 6 \\
Principal school/registrar (college) & 7 & 3 \\
Regional/area/national manager & 15 & 7 \\
Senior financial manager & 17 & 8 \\
\hline
\end{tabular}

\section{Table IV.} Lower and single point salary data

\begin{tabular}{lr}
\hline & \multicolumn{1}{c}{$€$} \\
\hline Lowest bottom salary point & 22,000 \\
Highest bottom salary point & 136,400 \\
Median bottom salary point & 50,000 \\
Mean bottom salary point & 56,523 \\
\hline
\end{tabular}


A total of 22 per cent of the advertisements stated that the positions were newly created. The most sought after management skills and competencies sought are reported in Table VI.

Of the recruitment notices, 30 per cent required in-depth knowledge of a particular field or subject. Personal skills sought in the advertisements are reported in Table VII.

A further 17 per cent sought a range of other personal skills and traits, mainly in the areas of ability to deliver and commercial/business acumen.

Experience was stated as essential in 77 per cent of the advertisements and advantageous in 1.5 per cent. Areas where experience was most required was at general manager level (21 per cent), senior management (12 per cent), human resource (HR) management (12 per cent) and financial management (10 per cent).

A total of 18 per cent stated that managers should be educated to degree or third level, 7 per cent sought postgraduate qualifications, 21 per cent stated a particular professional qualification, and 2 per cent sought a management qualification.

The vast majority of positions advertised (61 per cent) were located in the province of Leinster and the vast majority of these were located in or around the capital city of Dublin. A total of 19 per cent were located in the southern province of Munster, 4 per cent in the western province of Connaught and 5 per cent in Ulster (including Northern Ireland). The location of positions advertised in the remaining of 11 per cent of the advertisements were not stated.

Sources of data are reported in Table VIII.

\begin{tabular}{lrr}
\hline & $€$ & \\
\hline Lowest bottom salary point & 33,826 & \\
Highest bottom salary point & 167,497 & Table V. \\
Median bottom salary point & 59,384 & Higher point salary data \\
Mean bottom salary point & 65,864 & data
\end{tabular}

\begin{tabular}{lrr}
\hline Management skills/competencies area sought & Per cent & \\
Leadership and strategy & 21 & \\
Human resource management & 17 & Table VI. \\
Financial management & 13 & Management skills and \\
Change management & 8 & competencies sought \\
Managerial vision & 6 & \\
\hline
\end{tabular}

\begin{tabular}{lrr}
\hline Personal skills sought & Per cent \\
\hline Communications skills & 30 \\
Interpersonal/people skills & 24 \\
Teamworking & 19 \\
Networking & 11 & \\
Motivational abilities & 9 & Table VII. \\
Initiative and enthusiasm & 8 & Personal skills sought \\
Negotiating & 3 & \\
\hline
\end{tabular}


LODJ

25,3

286

As is noticeable from these statistics a significant amount of cross-advertising occurred. A total of 55 per cent of the advertisements appeared in one newspaper alone and 15 per cent appeared in three or more newspapers. It is important to note that one source should not be taken as being preferable to another. For example, only 39 per cent of the advertisements sourced from the Irish Independent also appeared in the Irish Times and the sole advertisement sourced from the Sunday Timesdid not appear in any other Irish national newspaper scanned. Gauging the full extent of the employment market for senior managers is dependent on scanning and reviewing as many data sources as possible.

\section{Results from qualitative comparative analysis}

Role and personal attributes

Clear differences emerge when sectors are analysed separately.

It appears from the data that senior management positions in the private sector place a strong emphasis on leadership, strategic and creative thinking, decision making team working and the management of business development and change. Appointees are expected to be responsible, strongly results-oriented, "hands on" and to have strong commercial acumen and communications skills.

Advertisements for similar positions in the public sector tend to emphasise management skills (in a general sense), relationship building and ability to manage change. As with the private sector, communications and interpersonal skills are important. Understanding of the environment in which the organisation operates is a strong requisite in most of the advertisements. The most noticeable difference between the public sector and private sector advertisements analysed is that there appears to be a stronger emotional appeal to applicants for public sector positions; the public sector advertisements are more likely to demand "passion" or a "personal commitment" to the area of work.

This emotional appeal is even more pronounced in the advertisements for senior management positions in the NGO sector as evidenced by the usage of terms such as "courage" and "inspiration" when stating personal traits required for the positions. Communications skills and networking abilities are also stated in stronger terms than the public sector advertisements. It is also interesting to note that personal drive, a "self-starter" mentality, energy and initiative are key requirements for senior NGO managers.

\section{Educational requirements}

Most of the private sector advertisements sought professional qualifications rather than academic qualifications. In the cases where degrees were sought, these were

Source of employment advertisements

Irish Times

Irish Independent

Sunday Independent

Irish Examiner

Sunday Business Post

Sunday Tribune
Per cent 
expected to be in conjunction with a finance or HR professional qualification. That said, two of the positions sought science-related doctorates.

Qualifications in public sector advertisements were not sought to the same extent as the private sector and it is interesting to note that degree or third level qualification requirements tended to be stated most in the NGO sector advertisements analysed. Evidence from the broader quantitative analysis supports this: 27 per cent of advertisements for the NGO sector required a degree or equivalent compared to 13 per cent of private sector advertisements and 18 per cent of public sector advertisements.

\section{Sectoral management cultures}

\section{Experience}

Analysis of the overall population reports that 84 per cent of private sector advertisements stated experience as essential, compared to 79 per cent of advertisements from NGOs and 68 per cent of public sector advertisements.

Advertisements for management positions in the private sector demonstrated a strong tendency to state an exact number of years of experience required as a minimum of candidates. Experience was sought in a variety of (sometimes quite specific) roles.

Public sector advertisements in general did not seek specific numbers of years of experience required for a post, but instead requested evidence of a career "track record”. Most of the experience required was at management level.

The NGO advertisements contained experience requirements which were sought in both the private and public sector advertisements: some stated the number of years required as experience, others sought evidence of track records; some sought general management experience and others sought experience in a specific area. Senior management positions in NGOs tended to require experience of successfully managing on a smaller scale (e.g. a small to medium-sized enterprise (SME), an entrepreneurial start-up or an international project).

\section{Package}

There were very clear differences in the ways that remuneration data were communicated for positions in the private and public sectors. Private sector advertisements tended not to state exact salary ranges, choosing instead to state that an "attractive package" would be made available to applicants. Some of the private sector advertisements mentioned other benefits such as shareholdings or cars. It is interesting to note that private sector advertisements also mentioned that a benefit of the role was membership of senior management. Career growth potential of the position was also communicated as an advantage attached to the position.

Public sector advertisements tended to state either the salary starting point or the full salary scale.

NGOs varied between stating the salary, mentioning that remuneration would be commensurate with qualifications and/or experience, stating an "attractive package" or (in two cases) not stating the salary at all.

These findings are reflected in results from an analysis of the overall population. Salary data were available for 52 per cent of public sector positions advertised, 36 per cent for NGO sector positions advertised and 9 per cent of private sector positions advertised. An analysis of salary data captured in the overall sample is presented in Table IX. 


\section{LODJ}

25,3
Method of responding to an advertisement

The private sector tended to request applicants for senior management positions to apply by submitting a CV with details of current salary and position. Though not as pronounced, this was also the tendency in the NGO sector. The advertisements for the public sector positions were divided between $\mathrm{CV}$ and application form submission.

\section{8}

\section{Discussion}

The identification of a single national management culture is greatly problematised when sectoral expectancies and needs are analysed. Although certain similarities emerge in each sector (e.g. communications and interpersonal skills are important for managers in all sectors) the comparative analysis of advertisements for senior management positions in each sector has demonstrated that clear differences in managerial cultures exist. These are summarised in Table X.

The similarity between certain sectors is interesting to note; in some circumstances the NGO sector advertisements were closer to the private sector advertisements than public sector advertisements.

\begin{tabular}{lccrc}
\hline Sector/salary point & $\begin{array}{c}\text { Minimum } \\
(€)\end{array}$ & $\begin{array}{c}\text { Maximum } \\
(€)\end{array}$ & $\begin{array}{c}\text { Mean } \\
(€)\end{array}$ & $\begin{array}{c}\text { Median } \\
(€)\end{array}$ \\
\hline Public (lower or single point stated) & 26,542 & 136,400 & 59,014 & 51,273 \\
Public (higher) & 33,826 & 167,497 & 65,282 & 58,339 \\
Private (lower or single point stated) & 22,000 & 100,00 & 61,324 & 61,923 \\
Private (higher) & 80,000 & 150,000 & 108,786 & 96,359 \\
NGO (lower or single point stated) & 33,826 & 57,628 & 42,474 & 41,012 \\
NGO (higher) & 41,068 & 72,211 & 53,560 & 50,000 \\
\hline
\end{tabular}

Table IX.

Comparison of sectoral salaries

\begin{tabular}{|c|c|c|c|}
\hline Category & Private sector tendency & Public sector tendency & NGO sector tendency \\
\hline Role and & Leadership & General management & Entrepreneurial/SME/project \\
\hline Personal & Strategic thinking & Networking /relationship & management \\
\hline \multirow[t]{5}{*}{ Attributes } & Decision making & building & Networking \\
\hline & Organisational change & Organisational change & Strategic thinking \\
\hline & /development & Understanding of field & Self-starter orientation \\
\hline & Results orientation & Emotional appeal & Drive/energy \\
\hline & Commercial acumen & & Strong emotional appeal \\
\hline Education & Professional qualification & $\begin{array}{l}\text { Split between professional } \\
\text { and academic } \\
\text { qualification }\end{array}$ & Academic qualification \\
\hline Experience & $\begin{array}{l}\text { Exact number of years } \\
\text { required }\end{array}$ & Track record required & $\begin{array}{l}\text { Split between exact number } \\
\text { of years and track record }\end{array}$ \\
\hline Package & $\begin{array}{l}\text { "Attractive package" and } \\
\text { benefits. Position stated } \\
\text { as a benefit }\end{array}$ & Exact salary stated & $\begin{array}{l}\text { Split between "attractive } \\
\text { salary" commensurate with } \\
\text { experience/qualification and } \\
\text { exact salary }\end{array}$ \\
\hline $\begin{array}{l}\text { Method of } \\
\text { responding }\end{array}$ & $\mathrm{CV}$ & Application form or $\mathrm{CV}$ & $\mathrm{CV}$ \\
\hline
\end{tabular}

Table X. Sectoral tendencies by category

\section{responding}


The research findings demonstrated that advertisements for managers communicated messages about the difference between management cultures when compared by sector. These differences highlight a number of areas that should be taken into account by management development organisations and functions. Not only do management development bodies work with individuals who are part of one particular key organisational sub-culture (the executive or management culture), but also these cultures differ according to the sector. Schein (1996) identified the global executive worldview as being "built around the necessity to maintain an organization's financial health and is preoccupied with boards, investors, and the capital markets. Executives may have other preoccupations, but they cannot get away from having to worry about and manage the financial survival and growth of their organization." The research found this to appear to be true for senior managers in private sector organisations, but was not as pronounced for managers in the public and NGO sectors. The recruitment data for public sector organisations sought a greater level of understanding of the environment in which their organisation operated, and higher levels of emotional involvement in relevant fields. Senior management positions in the private sector sought leadership competencies and the ability to drive organisational change; executive positions in the NGO sector sought senior managers with an entrepreneurial, "start-up" mindset.

It is certainly not the case that senior public sector and NGO executives are exempt from financial concerns. Schein (1996) lists one of the assumptions of the executive culture as: "The inherent value of relationships and community is lost as an executive rises in the hierarchy." It appears be the case that the culture of public sector bodies and NGOs requires greater levels of alignment of executive, operator and engineer cultures in order that these organisations may reach these goals. A hypothetical argument emerges that executive/management cultures differ fundamentally according to the general sector in which the organisation operates, and the major factors which drive this variation include the:

- degree of proximity of the executive/management culture to other key subcultures in the organisation; and

- personal attributes of managers working in each management culture.

The challenge for management development is to assist the identification of the differences between these sectoral management cultures so that learning can be concentrated around key areas specific to needs of organisations operating in a particular sector.

Opportunities for enhancing research in this field and to prove the hypothesis under development could be generated by:

- Expanding the range of data collected by increasing the data collection timeframe from three months to 12 months or longer

- Increasing ancillary resources mentioned in many of the advertisements, such as additional information available on Web sites, in application forms, job descriptions etc.

- Engaging executive recruitment agencies as partners in research. It is certain that many management positions that become available are not publicly advertised. 
LODJ

25,3

290

- Extending the range of sectoral sub-categories to enable a more focussed analysis of the executive cultures which may exist in, for example, the health, educational, financial, pharmaceutical, services sectors.

There are, of course, a range of methods for analysing organisational cultures and sub-cultures (Martin, 2001). The development and clarification of the hypothesis on sectoral management cultures requires validation through a much broader set of empirical indicators than is used here. Nevertheless, recruitment advertising provides a rich source of textual material whose content serves to attract prospective entrants to a management culture, and to dissuade those who will not "fit" with the orientation of this key organisational sub-culture. As a point-of-entry to a management culture, recruitment advertising for senior management positions provides important indications to the "character" of the sub-culture, and how it is differentiated from executive/management cultures in other sectors.

\section{References}

Ashkanasy, N.M., Trevor Roberts, E. and Earnshaw, L. (2002), "The Anglo Cluster: legacy of the British Empire”, Journal of World Business, Vol. 37, pp. 28-39.

Black, B. (1999), "National culture and high commitment management", Employee Relations, Vol. 21 No. 4, pp. 389-404.

Bryson, J. (1995), Strategic Planning for Public and Non-profit Organizations, Jossey-Bass, San Francisco, CA.

Communal, C. and Senior, B. (1999), "National culture and management: messages conveyed by British, French and German advertisement for managerial appointments", Leadership \& Organization Development Journal, Vol. 20 No. 4, pp. 26-35.

Cullen, J. (2000), “A review of library and information service job advertisements: what do they tell us about work in the Irish library sector", Journal of Information Science, Vol. 26 No. 4, pp. 278-81.

Dargie, C. (2000), "Observing chief executives: analysing behaviour to explore cross-sectoral differences”, Public Money \& Management, July-September, pp. 39-44.

Hofstede, G. (1980), Culture's Consequences: International Differences in Work-related Values, Sage, London.

Hofstede, G. (1991), Cultures and Organisations: Software of the Mind, McGraw-Hill Book Company, London.

Hofstede, G. (2001), Culture's Consequences: International Differences in Work-related Values, 2nd ed., Sage, London.

Kingston, W. (2001), "What can we do about the civil service?", Studies, Vol. 90 No. 359, pp. 320-30.

Lindholm, N. (2000), “(1999/ National culture and performance management in MNC subsidiaries”, International Studies of Management \& Organization, Vol. 29 No. 4, pp. 45-66.

Martin, J. (2001), Organizational Culture: Mapping the Terrain, Sage Publications, London.

Nolan, B., O'Connell, P.J. and Whelan, C.T. (2001), Bust to Boom?: The Irish Experience of Growth and Inequality, Economic and Social Research Institute/Institute of Public Administration, Dublin.

O’Sullivan, E. (1999), “Voluntary agencies in Ireland - what future role?", Administration, Vol. 47 No. 4, pp. 54-69. 
Pappas, A.T. (1996), Reengineering Your Non-profit Organization: A Guide to Strategic Transformation, John Wiley \& Sons, Chichester.

Parry, K.W. and Proctor-Thomson, S.B. (2003), "Leadership, culture and performance: the case of the New Zealand public sector”, Journal of Change Management, Vol. 3 No. 4, pp. 376-99.

\section{Sectoral management cultures}

Peillon, M. (2002), "Introduction", in Peillon, M. and Corcoran, M.P. (Eds), Ireland Unbound: A Turn of the Century Chronicle, Institute of Public Administration, Dublin.

Read, R. (1993), "Policies and politics of national economic growth", unpublished doctoral dissertation, Stanford University, Stanford, CA.

Robert, C., Probst, T.M., Martocchio, J.J., Drasgow, F. and Lawlor, J.J. (2000), "Employment and continuous improvement in the United States, Mexico, Poland, and India: predicting fit on the basis of power distance and individualism", Journal of Applied Psychology, Vol. 85 No. 5, pp. 643-58.

Schein, E.H. (1996), "Three cultures of management: the key to organisational learning”, Sloan Management Review, No. Fall, pp. 9-20.

Trompenaars, F. and Hampden-Turner, C. (1997), Riding the Waves of Culture: Understanding Cultural Diversity in Business, Nicholas Brealey, London.

Wilkins, A.L. and Ouchi, W.G. (1983), "Efficient cultures: exploring the relationship between culture and organizational performance", Administrative Science Quarterly, Vol. 28, pp. $468-81$. 